\title{
Surface-Confined Amorphous Films from Metal-Coordinated Simple Phenolic Ligands
}

\author{
Md. Arifur Rahim, ${ }^{\dagger}$ Kristian Kempe, ${ }^{\dagger, \S}$ Markus Müllner, ${ }^{\dagger, \#}$ Hirotaka Ejima, ${ }^{\dagger, \uparrow}$ Yi Ju, ${ }^{\dagger}$ Martin P. van \\ Koeverden, ${ }^{\dagger}$ Tomoya Suma, ${ }^{\dagger}$ Julia A. Braunger, ${ }^{\dagger}$ Michael G. Leeming, ${ }^{\ddagger} \|$ Brendan F. Abrahams, ${ }^{\ddagger}$ and \\ Frank Caruso ${ }^{*}$, \\ ${ }^{\dagger}$ ARC Centre of Excellence in Convergent Bio-Nano Science and Technology, and the Department of Chemical and \\ Biomolecular Engineering, The University of Melbourne, Parkville, Victoria 3010, Australia \\ ${ }^{\ddagger}$ School of Chemistry, The University of Melbourne, Parkville, Victoria 3010, Australia \\ "Bio21 Institute of Molecular Science and Biotechnology, The University of Melbourne, Parkville, Victoria 3010, Australia
}

\begin{abstract}
Coordination chemistry of natural polyphenols and transition metals allows rapid, self-assembly of conformal coatings on diverse substrates. Herein, we report that this coordination-driven self-assembly process applies to simple phenolic molecules with ditopic or monotopic chelating sites (as opposed to macromolecular, multitopic polyphenols), leading to surfaceconfined amorphous films upon metal coordination. Films fabricated from gallic acid, pyrogallol, and pyrocatechol, which are the major monomeric building blocks of polyphenols, have been studied in detail. Pyrocatechol, with one vicinal diol group (i.e., bidentate), has been observed to be the limiting case for such assembly. This study expands the toolbox of available phenolic ligands for the formation of surface-confined amorphous films, which may find applications in catalysis, energy, optoelectronics, and biomedical sciences.
\end{abstract}

\section{INTRODUCTION}

Modular control over the rational design of supramolecular architectures has been achieved in the last two decades by smart engineering of coordination-driven self-assembly processes. ${ }^{1}$ Early prediction of the inherent preferences for directionality and binding affinity within the complementary building blocks of coordination complexes has paved the way for fabricating structures with extended networks of metal clusters bridged by compatible organic ligands. ${ }^{2,3}$ Porous coordination polymers or metal-organic frameworks (MOFs) with distinct spatial and geometrical arrangements of the interconnecting motifs are examples of such organic-inorganic hybrid materials. ${ }^{4-7}$ These crystalline materials with structurally encoded nano- and micro-porosities have potential application for gas storage, separation and sensing. ${ }^{8-13}$ On the other hand, surface-bound or freestanding amorphous thin films/coatings are another class of network materials of importance in several branches of science, ${ }^{14-16}$ where polymeric (covalent) compounds are the predominantly used structural components. Research has also focused on exploring novel strategies to incorporate inorganic moieties in polymeric films to obtain hybrid functional materials that exploit the synergistic effects of the organic and inorganic constituents. $^{17,18}$ In this context, processes utilizing selfassembly of coordination complexes are a promising strategy toward facile engineering of thin films with defined properties.

Recently, we reported a facile assembly approach that exploits polyphenol-metal interactions, specifically between tannic acid (TA) and iron(III) (Fe ${ }^{\mathrm{III}}$ ) ions, to form thin films. ${ }^{19}$ Our interest in these metal-polyphenol systems arises from the facile and versatile nature of the assembly process, to produce tunable, dynamic materials. Using TA as a versatile ligand, we demonstrated the formation of capsules with engineered $\mathrm{pH}$ responsive degradation, luminescence and positron emission, by judicious choice of the incorporated metal, ${ }^{20}$ as well as $\mathrm{pH}$ responsive drug delivery vectors ${ }^{21}$ and cytoprotective coatings. $^{22}$ Furthermore, we reported the assembly of $\mathrm{Fe}^{\mathrm{III}}$ polyphenol capsules from a synthetic poly(ethylene glycol)based polyphenol, which exhibited reduced protein fouling and non-specific cellular association compared to $\mathrm{TA} / \mathrm{Fe}^{\mathrm{III}}$ capsules. ${ }^{23}$ For the TA systems, initiation of the film assembly is likely to occur by adsorption of TA to the surface and subsequent strong intermolecular (and possibly intramolecular) crosslinking by the metal ions. Film formation was rationalized by the strong affinity of polyphenols for various surface chemistries, and the polymeric, multitopic structure of TA containing multiple galloyl groups covalently attached to a central glucose core. However, whether the amorphous nature of the films originates from the asymmetry of TA or from a generic interfacial behavior of metal-phenolic ligand interactions is unclear. MOF synthesis studies show that simple ditopic or tritopic ligands, even with symmetric binding sites, can produce stable kinetically trapped amorphous phases (byproduct or major product) in bulk depending on the choice of ligand/metal pair and synthetic conditions. $^{1,3,24-27}$ It remains to be determined whether the amorphous network of TA and metal ions formed on surfaces is limited to polyphenols (i.e., multiple binding/chelating sites with structural asymmetry) or is more a generic phenomenon 
(i.e., kinetic assembly) that can be expanded to simple phenolic ligands with few binding/chelating sites.

In our effort to understand these types of metal-phenolic systems, we have discovered that phenolic ligands containing single aromatic rings with ditopic or monotopic chelating groups are also able to form continuous films on solid surfaces through coordination interactions with metal ions. Each of the phenolic ligands, namely gallic acid (GA), pyrogallol (PG) and pyrocatechol (PC), resulted in instantaneous film formation on substrate surfaces upon coordination with $\mathrm{Fe}^{\mathrm{III}}$ ions. Network/film formation by these simple ligands is discussed in detail considering different interactions and growth conditions. From structural considerations of the diverse library of phenolics, it can be concluded that at least one vicinal diol group (bidentate) is essential to form an amorphous film, leaving PC as the limiting case for such phenolic-metal assemblies.

\section{EXPERIMENTAL SECTION}

Materials. Gallic acid (GA, 97.5 - 102.5\%), pyrogallol (PG, $99.0 \%$ ), pyrocatechol ( $\mathrm{PC}, \geq 99.0 \%$ ), phloroglucinol ( $\geq 99.0 \%$ ), phenol $(\geq 99.0 \%)$ iron(III) chloride hexahydrate $\left(\mathrm{FeCl}_{3} .6 \mathrm{H}_{2} \mathrm{O}\right)$, poly(ethyleneimine) (PEI, $\left.M_{\mathrm{w}}=25 \mathrm{kDa}\right)$, poly(acrylic acid) (PAA, $M_{\mathrm{w}}=10 \mathrm{kDa}$ ), sodium citrate, citric acid, glycine, sodium hydroxide $(\mathrm{NaOH})$, and fluorescein isothiocyanate dextran (FITC-dextran) with various $M_{\mathrm{w}}$ (70, 250, 500, $2000 \mathrm{kDa}$ ) and $N$-methyl-2-pyrrolidone (NMP) were purchased from Sigma-Aldrich and used as received. Polystyrene (PS) particles $(D=3.55 \pm 0.07 \mu \mathrm{m})$, aminated silica particles $(D=3.07 \pm 0.12 \mu \mathrm{m})$, melamine formaldehyde (MF) particles $(D=2.98 \pm 0.06 \mu \mathrm{m})$ and poly(methyl methacrylate) (PMMA) particles $(D=3.67 \pm 0.08 \mu \mathrm{m})$ were purchased from Microparticles GmbH. Poly(lactic acid) (PLA) particles (polydisperse), and poly(lactic-Co-glycolic acid) (PLGA) particles $(D=\sim 2 \mu \mathrm{m})$ were obtained from Corpuscular Inc. Tetrahydrofuran (THF) and acetone were purchased from Chem Supply. High-purity (Milli-Q) water with a resistivity of $18.2 \mathrm{M} \Omega \mathrm{cm}$ was obtained from an inline Millipore RiOs/Origin water purification system.

Film Formation on Particulate Substrates. GA/Fe ${ }^{\mathrm{III}}$ and PG/Fe ${ }^{\text {III }}$ Systems. The standard protocol is described as follows. $50 \mu \mathrm{L}$ of polystyrene (PS, $D=3.55 \pm 0.07,10 \mathrm{wt} \%$ water suspension) particles was first washed twice with MilliQ water. Then, $400 \mu \mathrm{L}$ of the ligand (GA or PG) solution $(15 \mathrm{mM})$ was added to the PS particles and vortexed for $10 \mathrm{~s}$. $200 \mu \mathrm{L}$ of $\mathrm{FeCl}_{3} \cdot 6 \mathrm{H}_{2} \mathrm{O}(30 \mathrm{mM})$ solution was then added and quickly vortexed for 3-4 s. Subsequently, the mixture $\mathrm{pH}$ was raised by addition of $20 \mu \mathrm{L}$ of $0.5 \mathrm{M} \mathrm{NaOH}$ solution, followed by vortexing for $1 \mathrm{~min}$; the final $\mathrm{pH}$ values of the mixtures were $\sim 3.8$ and $\sim 4.1$ for the $\mathrm{GA} / \mathrm{Fe}^{\mathrm{III}}$ and $\mathrm{PG} / \mathrm{Fe}^{\mathrm{III}}$ systems, respectively. Unreacted supernatant was removed by centrifugation (1700 g, $1 \mathrm{~min}$ ) followed by four washing steps in Milli-Q water. Dissolution of the PS cores was accomplished by washing the pellets with THF three times (1900 g, $1 \mathrm{~min}$ ). The obtained hollow capsules were washed twice (2000 $g, 3 \mathrm{~min}$ ) with Milli-Q water and finally resuspended in $400 \mu \mathrm{L}$ of Milli-Q water for characterization. Variation in the $\mathrm{pH}$ values of the film formation mixtures was also performed. For the $\mathrm{GA} / \mathrm{Fe}^{\mathrm{III}}$ system, stable film formation was observed within the $\mathrm{pH}$ range of 2.5 to 4.8 . The $\mathrm{pH}$ values of the final mixtures in these cases were adjusted by adding small volumes of $0.1 \mathrm{M} \mathrm{HCl}$ or $0.1 \mathrm{M} \mathrm{NaOH}$ solutions. Coating GA/Fe ${ }^{\mathrm{III}}$ on aminated-SiO 2 , PMMA, PLA, or PLGA particles was performed in the same manner as described above, except that the PMMA and PLA particles were dissolved using 1:1 v/v acetone:NMP to obtain hollow capsules. Film formation (on PS particles) was also conducted by varying the starting concentrations of $\mathrm{GA}$ and $\mathrm{Fe}^{\mathrm{III}}$ solutions from 7.5 to $20 \mathrm{mM}$, while keeping the $\mathrm{pH}$ and stoichiometry (ligand to metal 1:1) of the final mixture constant. For sequential assembly (multiple cycles) experiments, the standard film formation protocols described above were repeated.

$\mathbf{P C} / \mathbf{F e}^{\text {III }}$ System. The standard protocol is described as follows. Milli-Q water used for this system was degassed by $\mathrm{N}_{2}$ bubbling for $15 \mathrm{~min}$. $50 \mu \mathrm{L}$ of polystyrene (PS, $D=3.55 \pm 0.07,10 \mathrm{wt} \%$ water suspension) particles was first washed twice with Milli-Q water. Then, $400 \mu \mathrm{L}$ of PC solution (15 $\mathrm{mM})$ was added to the PS particles and vortexed for $10 \mathrm{~s}$. Subsequently, $200 \mu \mathrm{L}$ of $\mathrm{FeCl}_{3} \cdot 6 \mathrm{H}_{2} \mathrm{O}$ (30 mM) solution was added and the resultant mixture was vortexed for $1 \mathrm{~min}$. Note that no additional $\mathrm{pH}$ adjustment is required for this system; the final $\mathrm{pH}$ value of the mixture was $\sim 2.1$. Unreacted supernatant was removed by centrifugation (1700 $\mathrm{g}$, $1 \mathrm{~min}$ ) and subsequent washing steps (four times) in Milli-Q water. Dissolution of the PS templates was accomplished by washing the pellets with THF three times (1900 $\mathrm{g}, 1 \mathrm{~min})$. The obtained hollow capsules were washed twice $(2000 \mathrm{~g}$, $3 \mathrm{~min})$ with Milli-Q water and finally resuspended in $400 \mu \mathrm{L}$ of Milli-Q water for characterization. Variation in the $\mathrm{pH}$ values of the film formation mixtures was also performed. For the PC/Fe ${ }^{\text {III }}$ system, stable film formation was observed within the $\mathrm{pH}$ range of 1.8 to 2.4. The $\mathrm{pH}$ values of the final mixtures in these cases were adjusted by adding small volumes of $0.1 \mathrm{M}$ $\mathrm{HCl}$ or $0.1 \mathrm{M} \mathrm{NaOH}$ solutions. Coating of aminated- $\mathrm{SiO}_{2}$, PMMA, PLA, or PLGA particles was performed in the same manner as above, except that PMMA and PLA particles were dissolved in 1:1 v/v acetone:NMP to obtain hollow capsules. Film formation (on PS particles) was also conducted by varying the starting concentrations of $\mathrm{PC}$ and $\mathrm{Fe}^{\mathrm{III}}$ solutions from 12.5 to $20 \mathrm{mM}$, while keeping stoichiometry (ligand to metal ratio as 1:1) of the final mixture constant. For sequential assembly (multiple cycles) experiments, the standard film formation protocols described above were repeated.

Film Formation on Planar Substrates. Substrates used for these experiments were PS, PDMS, and quartz, which were cut into suitable sized pieces. Piranha-cleaned quartz substrates were primed with a PEI layer by dipping the substrates in PEI ( $2 \mathrm{mg} \mathrm{mL}^{-1}, 0.5 \mathrm{M} \mathrm{NaCl}$ ) solution for 15 min, rinsed in Milli-Q water and dried in $\mathrm{N}_{2}$ flow. Caution! Piranha solution is highly corrosive! Care should be taken during preparation. Piranha-cleaned quartz substrates were also primed with a PEI/PAA bilayer by dipping the substrates alternately in PEI (2 mg mL $\left.\mathrm{mL}^{-1}, 0.5 \mathrm{M} \mathrm{NaCl}\right)$ and PAA (2 $\mathrm{mg} \mathrm{mL}^{-1}, 0.5 \mathrm{M} \mathrm{NaCl}$ ) solution for $15 \mathrm{~min}$ with an intermediate rinsing (Milli-Q water) and drying $\left(\mathrm{N}_{2}\right)$ step. After applying the PAA layer the substrates were rinsed in Milli-Q water and dried in $\mathrm{N}_{2}$ flow. PS and PDMS substrates were plasma treated to render them hydrophilic prior to $\mathrm{GA} / \mathrm{Fe}^{\mathrm{III}}$ or $\mathrm{PC} / \mathrm{Fe}^{\mathrm{III}}$ coating. Process parameters were maintained the same as the standard protocols used for the particulate coatings for both systems. For the GA/Fe ${ }^{\text {III }}$ system, a substrate was placed in a $15 \mathrm{~mL}$ tube and $4 \mathrm{~mL}$ of GA solution (15 mM) was added and vortexed for $10 \mathrm{~s}$. 
Subsequently $2 \mathrm{~mL}$ of $\mathrm{Fe}^{\mathrm{III}} \mathrm{Cl}_{3} \cdot 6 \mathrm{H}_{2} \mathrm{O}(30 \mathrm{mM})$ solution was added and quickly vortexed for 3-4 s. $200 \mu \mathrm{L}$ of $0.5 \mathrm{M} \mathrm{NaOH}$ solution was immediately added to the mixture and vortexed for $1 \mathrm{~min}$. The substrate was then rinsed with Milli-Q water and dried with a $\mathrm{N}_{2}$ stream. For the $\mathrm{PC} / \mathrm{Fe}^{\mathrm{III}}$ system, a substrate was placed in a $15 \mathrm{~mL}$ tube and $4 \mathrm{~mL}$ of PC solution (15 mM) was added and vortexed for $10 \mathrm{~s}$. Subsequently $2 \mathrm{~mL}$ of $\mathrm{FeCl}_{3} \cdot 6 \mathrm{H}_{2} \mathrm{O}(30 \mathrm{mM})$ solution was added and vortexed for $1 \mathrm{~min}$. The substrate was then rinsed with Milli-Q water and dried with a $\mathrm{N}_{2}$ stream. For both systems the coating processes were repeated three times to enhance the color difference. UVVis absorption spectra were recorded after each cycle for quartz substrates (primed with PEI) using a solid sample holder.

\section{RESULTS AND DISCUSSION}

Figure 1 gives an overview of the results obtained for the different phenolic ligands, showing the $\mathrm{GA} / \mathrm{Fe}^{\mathrm{III}}, \mathrm{PG} / \mathrm{Fe}^{\mathrm{III}}$ and $\mathrm{PC} / \mathrm{Fe}^{\mathrm{III}}$ systems. Using particulate substrates, spherical freestanding films commonly known as capsules, were obtained after dissolving the templates in suitable solvents. ${ }^{28}$ Particulate substrates are advantageous because film formation and stability can be examined immediately after their removal. $\mathrm{GA} / \mathrm{Fe}^{\mathrm{III}}$, $\mathrm{PG} / \mathrm{Fe}^{\mathrm{III}}$ and $\mathrm{PC} / \mathrm{Fe}^{\mathrm{III}}$ capsules obtained using polystyrene (PS) particles as templates exhibited different colors (Figure 1b,d,f, respectively). UV-Vis absorption spectra for $\mathrm{GA} / \mathrm{Fe}^{\mathrm{III}}, \mathrm{PG} / \mathrm{Fe}^{\mathrm{III}}$ and $\mathrm{PC} / \mathrm{Fe}^{\mathrm{III}}$ capsules (Figure 1g-i) showed maxima $\left(\lambda_{\max }\right)$ in the visible region around $\sim 570 \mathrm{~nm}$, $\sim 619 \mathrm{~nm}$, and $\sim 680 \mathrm{~nm}$, respectively. These bands are significantly different from the absorption bands of the ligands themselves, and likely arise from charge transfer (CT) bands, ${ }^{29,30}$ which indicate the presence of metal-ligand coordination. Differential interference contrast (DIC) microscopy images of the corresponding systems showed stable and monodisperse capsules, which retained their spherical shape after template removal (Figure 1j-l). From microelectrophoresis measurements of these systems on PS particles, zeta $(\zeta)$-potentials were found to be $-39 \pm 4$, $-38 \pm 5$, and $-43 \pm 6 \mathrm{mV}$ for the $\mathrm{GA} / \mathrm{Fe}^{\mathrm{III}}, \mathrm{PG} / \mathrm{Fe}^{\mathrm{III}}$ and $\mathrm{PC} / \mathrm{Fe}^{\mathrm{III}}$ systems, respectively. Bare PS particles showed a $\zeta$ potential of $-42 \pm 5 \mathrm{mV}$. Generally, particles with $\zeta$-potential values higher than $\pm 30 \mathrm{mV}$ are considered to be stable against agglomeration because of the strong repulsive forces among the particles. ${ }^{31,32}$ Atomic force microscopy (AFM) performed on the air-dried capsules revealed surface features with folds and creases typical of collapsed capsule films (Figure 1m-o). Analyses of the collapsed flat regions of the $\mathrm{GA} / \mathrm{Fe}^{\mathrm{III}}$ and $\mathrm{PC} / \mathrm{Fe}^{\mathrm{III}}$ systems indicated smooth films with roughness values (rms) of $\sim 0.3$ and $\sim 0.4 \mathrm{~nm}$, respectively, whereas $\mathrm{PG} / \mathrm{Fe}^{\mathrm{III}}$ films showed a slightly rugged surface with a roughness value (rms) of $\sim 1 \mathrm{~nm}$. Single-wall film thicknesses from the AFM height profiles were determined to be $10.1 \pm 0.5,11.2 \pm 0.8$, and $11.4 \pm 0.4 \mathrm{~nm}$ for $\mathrm{GA} / \mathrm{Fe}^{\mathrm{III}}, \mathrm{PG} / \mathrm{Fe}^{\mathrm{III}}$, and $\mathrm{PC} / \mathrm{Fe}^{\mathrm{III}}$ systems, respectively. Similar surface morphologies with folds and creases were observed by transmission electron microscopy (TEM) (Figure 1p-r). The presence of $\mathrm{Fe}^{\mathrm{III}}$ ions in the films was confirmed by energy-dispersive X-ray spectroscopy (EDX) analyses (Figure S1).
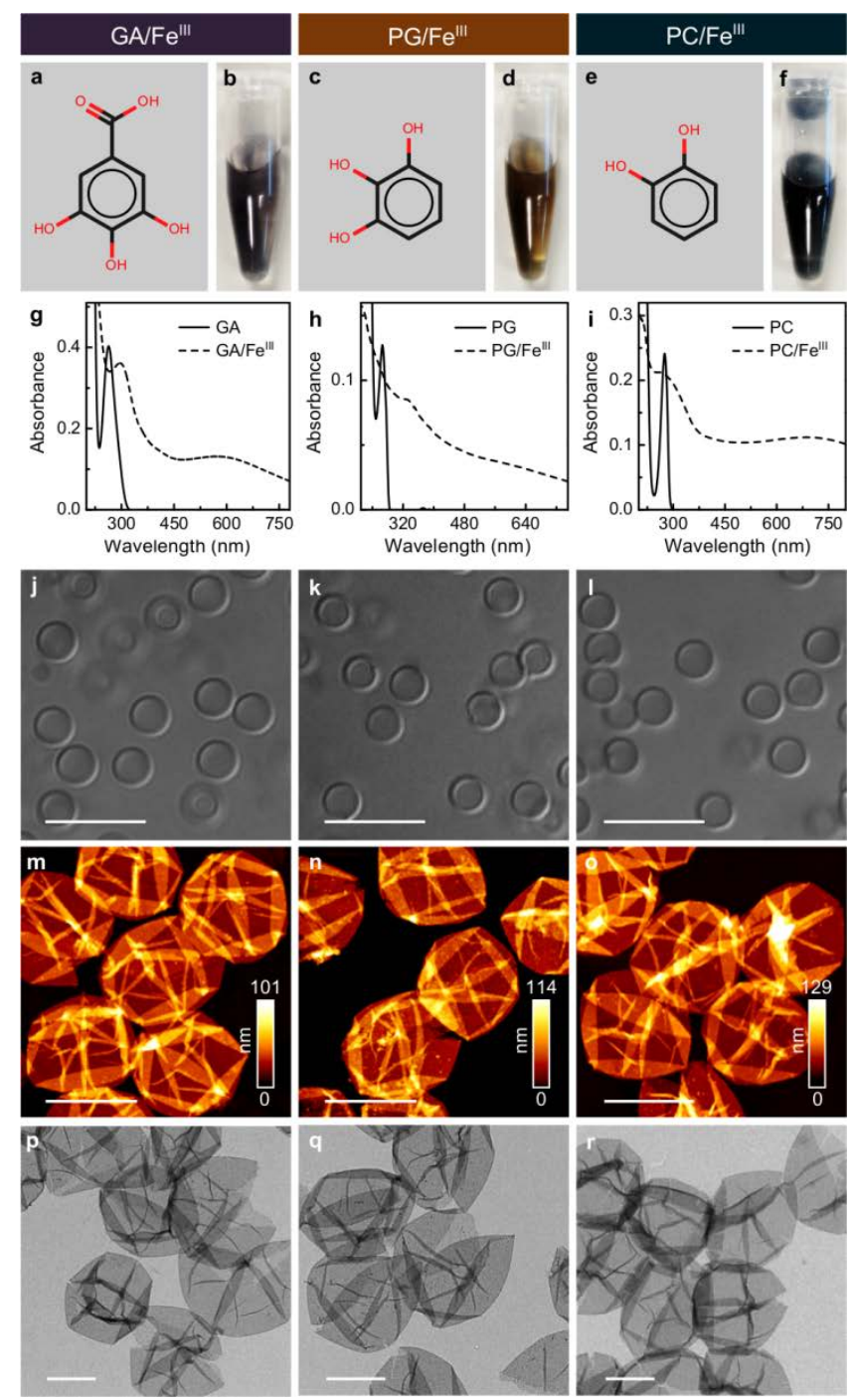

Figure 1. General characterization of $\mathrm{GA} / \mathrm{Fe}^{\mathrm{III}}, \mathrm{PG} / \mathrm{Fe}^{\mathrm{III}}$, and $\mathrm{PC} / \mathrm{Fe}^{\mathrm{III}}$ capsules. Each column represents one system. 2D structures of GA, PG, and PC (a, c, and e, respectively). Photographs (b, d, and f, respectively) showing capsule suspensions of $\mathrm{GA} / \mathrm{Fe}^{\mathrm{III}}, \mathrm{PG} / \mathrm{Fe}^{\mathrm{III}}$, and $\mathrm{PC} / \mathrm{Fe}^{\mathrm{III}}$ systems, respectively, in Milli-Q water. UV-Vis absorbance spectra showing the CT bands for the corresponding systems (g-i). Absorbance spectra of the ligand solutions are also presented for comparison. Aggregation-free, well-dispersed capsules are evident from the DIC images (j-l, scale bars correspond to $10 \mu \mathrm{m}$ ) for each system. AFM (m-o, scale bars correspond to $3 \mu \mathrm{m})$ and TEM (p-r, scale bars correspond to $2 \mu \mathrm{m}$ ) images correspond to the collapsed (dried) capsules for each system. 


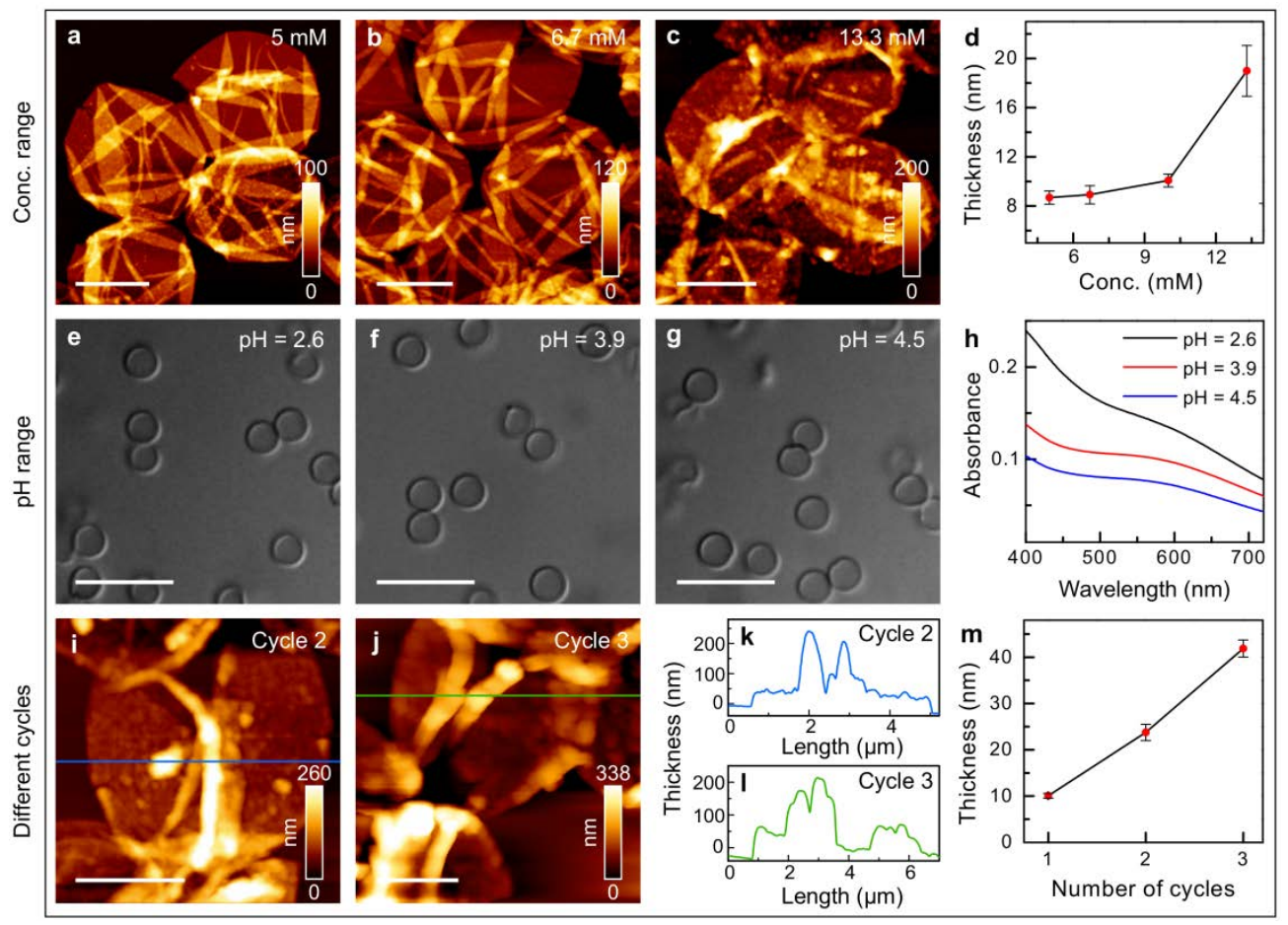

Figure 2. Characterization of the $\mathrm{GA} / \mathrm{Fe}^{\mathrm{III}}$ system with varying process parameters. AFM topographic images (a-c) of collapsed (dried) $\mathrm{GA} / \mathrm{Fe}^{\mathrm{III}}$ capsules at different starting concentrations of $\mathrm{GA}$ and $\mathrm{Fe}^{\mathrm{III}}\left(\mathrm{GA}: \mathrm{Fe}^{\mathrm{III}}=1: 1\right)$ showing surface morphologies of the capsules and the corresponding thicknesses, as measured by AFM height analyses (d). DIC images (e-g) of GA/Fe $\mathrm{F}^{\mathrm{III}}$ capsules prepared at different pH values of the mixture ( $\mathrm{GA}$ and $\mathrm{Fe}^{\mathrm{III}}$ ) and the corresponding changes in the CT bands, as observed by UV-Vis absorption spectra (h). AFM topographic images $\left(i, j\right.$ ) and height profiles (k, l)of collapsed (air-dried) GA/Fe ${ }^{\text {III }}$ capsules at different cycles showing surface morphologies of the capsules and the corresponding thicknesses, as measured by AFM height analyses (m) with different cycles. AFM scale bars correspond to $2 \mu \mathrm{m}$ and DIC scale bars correspond to $10 \mu \mathrm{m}$.

Next, we focused on the $\mathrm{GA} / \mathrm{Fe}^{\mathrm{III}}$ and $\mathrm{PC} / \mathrm{Fe}^{\mathrm{III}}$ systems as the simplest model ditopic and monotopic chelating ligand (phenolic type) systems, respectively, to further examine the film formation process with different process parameters. Previous work has shown that GA and $\mathrm{Fe}^{\mathrm{III}}$ form crystalline coordination frameworks. ${ }^{33,34}$ This system thus allows an important comparison highlighting the differences in material structure (crystalline frameworks versus amorphous thin films) that results from varied assembly conditions (vide infra). Figure 2 displays the results of the $\mathrm{GA} / \mathrm{Fe}^{\mathrm{III}}$ film formation using different concentrations and $\mathrm{pH}$ conditions. The final concentrations of the ligand/metal varied from $5 \mathrm{mM}$ to 13.3 $\mathrm{mM}$ while maintaining a [GA]:[Fe $\left.{ }^{\mathrm{III}}\right]$ stoichiometry of $1: 1$ The $\mathrm{GA} / \mathrm{Fe}^{\mathrm{III}}$ films formed showed a nonlinear trend of increasing thickness with increasing concentration. Smooth films were evident up to a concentration of $10 \mathrm{mM}$; however, at $13.3 \mathrm{mM}$ the films became rougher and thicknesses increased to $20 \mathrm{~nm}$ (Figure 2a-d). Alterations of the $\mathrm{pH}$ values of the mixture from 2.6 to 4.5 did not alter the stability of the capsules, as displayed by the DIC images of the stable capsules (Figure 2eg). The CT bands in the UV-Vis absorption spectra showed slight red shifts with decreasing $\mathrm{pH}$, accompanied by changes in the band shapes (Figure 2h). Repetition of the film formation cycle increased the film thicknesses from $\sim 10 \mathrm{~nm}$ for the first cycle to $\sim 40 \mathrm{~nm}$ for the third cycle (Figure 2i-m). Film formation was also studied on both planar and particulate substrates with different surface chemistries. Figure S2a-e (top panel) shows the film formation on different particulate templates, as is evident from the dark colored pellets after coating. DIC images of freestanding capsules obtained after poly(lactic acid) (PLA) and poly(methyl methacrylate) (PMMA) template removal are presented (Figure S2f,g, top panel). Photographs of $\mathrm{GA} / \mathrm{Fe}^{\text {III }}$ films deposited on various planar supports such as PS, quartz, and polydimethylsiloxane (PDMS) are displayed in Figure S2a-d (bottom panel). The intensity of the CT band at $\sim 570 \mathrm{~nm}$ increased with an increasing number of cycles on planar quartz substrates (Figure S2e, bottom panel). Similar experiments were performed on the $\mathrm{PC} / \mathrm{Fe}^{\mathrm{III}}$ system and presented in Figures S3 and S4. The concentration ( 8.3 to $13.3 \mathrm{mM}$ ) and $\mathrm{pH}$ (1.8 to 2.2) ranges for stable $\mathrm{PC} / \mathrm{Fe}^{\mathrm{III}}$ film formation were narrower than those for the $\mathrm{GA} / \mathrm{Fe}^{\mathrm{III}}$ system. An acidic $\mathrm{pH}$ for both systems was found to be crucial for film formation, which differs compared to the TA/Fe ${ }^{\text {III }}$ system, which forms films at $\mathrm{pH}$ 7.4. ${ }^{19} \mathrm{GA}$ and $\mathrm{PC}$ forms predominantly tris-type $\mathrm{e}^{29}$ complexes with $\mathrm{Fe}^{\mathrm{III}}$ at basic $\mathrm{pH}$ and possibly such complexes are not suitable for extended network formation (vide infra).

Several properties, namely, disassembly, permeability, and Young's moduli $\left(E_{Y}\right)$, of the $\mathrm{GA} / \mathrm{Fe}^{\mathrm{III}}$ and $\mathrm{PC} / \mathrm{Fe}^{\mathrm{III}}$ capsule systems were also investigated. Disassembly of $\mathrm{GA} / \mathrm{Fe}^{\text {III }}$ and $\mathrm{PC} / \mathrm{Fe}^{\mathrm{III}}$ capsules dispersed in solutions with different $\mathrm{pH}$ values was monitored by following the decrease of CT band intensity over time (Figures 3a and S5). Over $90 \%$ of GA/Fe $\mathrm{FII}^{\mathrm{III}}$ capsules disassembled within $10 \mathrm{~min}$ in solutions of $\mathrm{pH} 2$ 

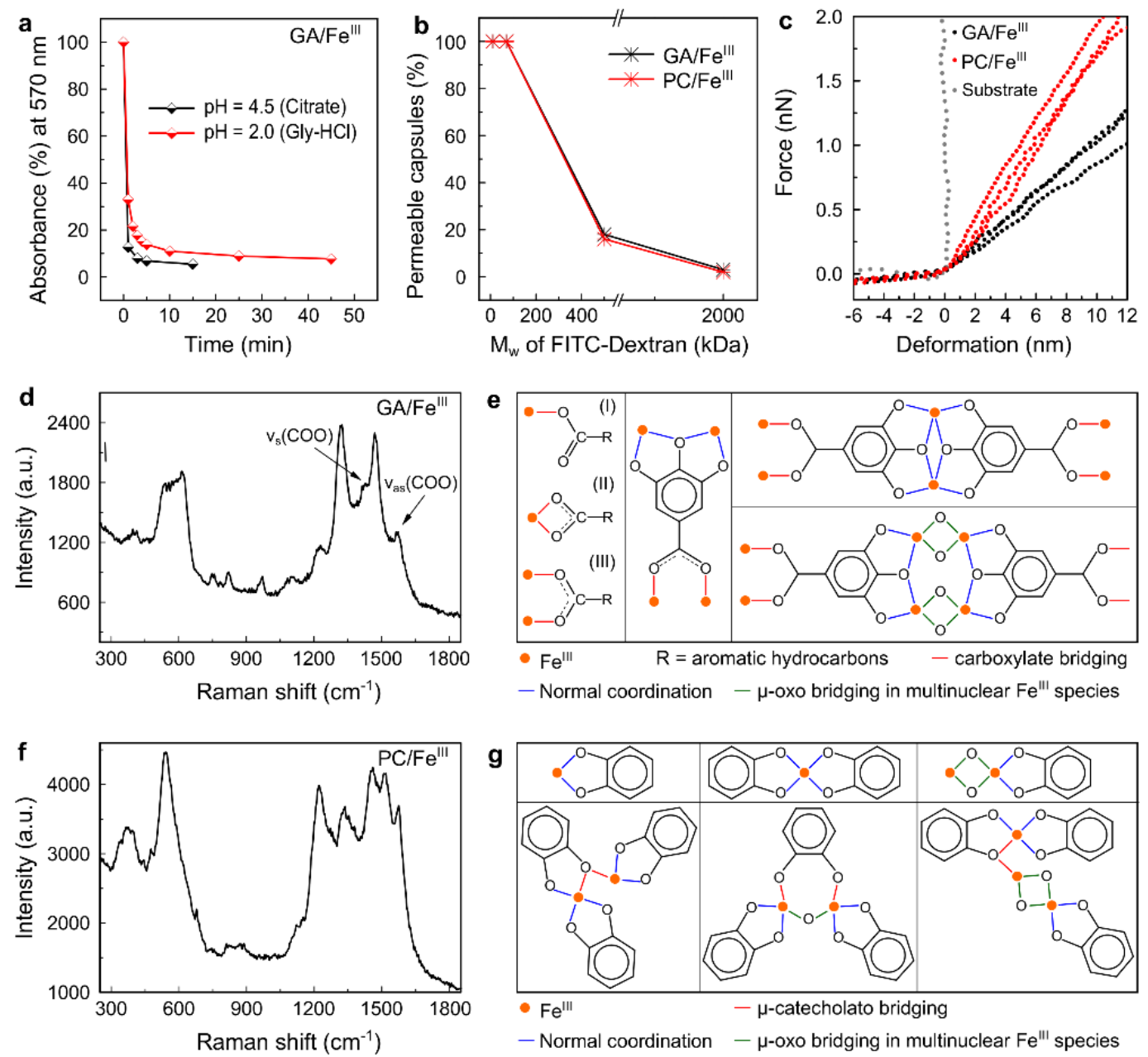

Figure 3. Properties and possible networks formation pathways of the $\mathrm{GA} / \mathrm{Fe}^{\mathrm{III}}$ and PC/Fe ${ }^{\mathrm{III}}$ systems. Disassembly profile (a) for $\mathrm{GA} / \mathrm{Fe}^{\mathrm{III}}$ capsules monitored by UV-Vis absorption spectroscopy. Disassembly of the capsules was confirmed by DIC microscopy after the UV-Vis absorption experiments. Permeability (b) of GA/Fe ${ }^{\mathrm{III}}$ and PC/Fe ${ }^{\mathrm{III}}$ capsules with respect to different $M_{\mathrm{w}}$ of FITCDextran. Representative force-deformation curves (c) for the small deformation regime of GA/Fe ${ }^{\text {III }}$ (black) and PC/Fe ${ }^{\text {III }}$ (red) capsules. Force-deformation curve for hard substrate is also presented for comparison. RR spectra (d and f) of GA/Fe ${ }^{\text {III }}$ and $\mathrm{PC} / \mathrm{Fe}^{\mathrm{III}}$, respectively. RR spectra were collected by an excitation wavelength of $782 \mathrm{~nm}$. Different coordination modes for the -COOH group (e, left most column, i-iii) and galloyl group (the rest of e) of GA for the GA/Fe ${ }^{\text {III }}$ system (coordination modes are based on Refs. 33,34,53). Different coordination modes (g) for the vicinal diol group of PC in the PC/Fe ${ }^{\text {III }}$ system. Note that these coordination species have available binding sites (not shown) to form a large network/film. Coordinated $\mathrm{H}_{2} \mathrm{O}$ molecules are omitted for clarity.

(glycine-HCl buffer) and $\mathrm{pH} 4.5$ (citrate buffer), respectively (Figures $3 \mathrm{a}$ and $\mathrm{S} 5 \mathrm{a}, \mathrm{b}$ ). In comparison, $\mathrm{PC} / \mathrm{Fe}^{\mathrm{III}}$ capsules showed over $70 \%$ disassembly when dispersed in solutions of $\mathrm{pH} 1.5$ and $\mathrm{pH} 4.5$ (citrate buffer) at 40 and 20 min (Figure S5c-e), respectively. Both types of capsules were permeable (Figure $3 \mathrm{~b}$ ) to 10 and $70 \mathrm{kDa}$ FITC-dextran, and over $80 \%$ and $95 \%$ of the capsules were impermeable to $500 \mathrm{kDa}$ and 2000 $\mathrm{kDa}$ FITC-dextran, respectively. The $E_{Y}$ for $\mathrm{GA} / \mathrm{Fe}^{\mathrm{III}}$ and $\mathrm{PC} / \mathrm{Fe}^{\mathrm{III}}$ capsules were estimated to be $620 \pm 200 \mathrm{MPa}$ and $870 \pm 240 \mathrm{MPa}$, respectively (Figure 3c) by AFM force measurements with a colloidal indenter. Comparing these values to the previously reported $\mathrm{TA} / \mathrm{Fe}^{\mathrm{III}}$ capsules $\left(E_{Y}=1 \pm\right.$ $0.2 \mathrm{GPa}),{ }^{19}$ it is evident that both $\mathrm{GA} / \mathrm{Fe}^{\mathrm{III}}$ and $\mathrm{PC} / \mathrm{Fe}^{\mathrm{III}}$ capsules are less rigid than $\mathrm{TA} / \mathrm{Fe}^{\mathrm{III}}$ capsules. This difference is attributed to their different molecular structures and coordination modes during film formation.
As demonstrated, the three ligands (GA, PG and PC) were suitable to form free-standing films with distinct properties. However, attempts to form surface-confined films from a monodentate tritopic ligand (phloroglucinol, 1,3,5trihydroxybenzene)) and a monodentate monotopic ligand (phenol) were unsuccessful. These results suggest that the presence of at least one vicinal diol group (i.e., bidentate) in the aromatic ring, as in PC, is a prerequisite for film formation (phenolic type ligand). It was hypothesized that metal-ligand coordination (vide infra) is the principal interaction mode for extended network and surface film formation. Thus the binding strength and stability of the complexes, and binding site availability to extend long range networks, were expected to be major factors influencing film formation. From the structures of phenol and phloroglucinol, we propose that the monodentate nature of these ligands does not favor a surfaceconfined film formation process. 
The visual colors of the films and the CT bands suggest metal coordination as a major mode for the formation of the long range networks. The broadness of the CT bands further indicates the involvement of different types of coordination species (mono, bis, bridging, etc.) in films. To obtain better insight into the film formation process, X-ray photoelectron spectroscopy (XPS), resonance Raman (RR) spectroscopy and electrospray ionization mass spectrometry (ESI-MS) were employed. XPS data for $\mathrm{GA} / \mathrm{Fe}^{\mathrm{III}}$ and $\mathrm{PC} / \mathrm{Fe}^{\mathrm{III}}$ films revealed that the Fe $2 \mathrm{p}_{3 / 2}$ signal showed a main peak around $\sim 712 \mathrm{eV}$ with a 2 p peak separation of $\sim 14 \mathrm{eV}$, which is consistent with the presence of $\mathrm{Fe}^{\mathrm{III}}$ being the dominant species in the films (Figure S6). ${ }^{35}$ These results also indicate that the role of redox intermediates in the films is negligible (vide infra). RR spectra of pristine GA and PC (Figure S7) compared to GA/Fe $\mathrm{Fe}^{\mathrm{III}}$ and $\mathrm{PC} / \mathrm{Fe}^{\mathrm{III}}$ films (Figure 3d,f) respectively, revealed clear differences between pristine and coordinated forms of the ligands. Raman bands of the $\mathrm{GA} / \mathrm{Fe}^{\mathrm{III}}$ films at 1470,1315 , and $1230 \mathrm{~cm}^{-1}$ can be assigned to the skeletal modes of the substituted benzene ring. ${ }^{36,37}$ Bands in the low frequency region of 650-500 (broad due to multiple peaks), and $400 \mathrm{~cm}^{-1}$ (very weak) can be attributed to the Fe-O vibration $\left(v_{\mathrm{Fe}-\mathrm{O}}\right)$ arising from galloyl-Fe coordination. ${ }^{36,37}$ Moreover, bands at 1570 (asymmetric, $v_{\text {as }}$ ) and 1428 (symmetric, $v_{\mathrm{s}}$ ) $\mathrm{cm}^{-1}$ can be assigned to carboxylate (-COO)/Fe ${ }^{\text {III }}$ interactions, and the difference $\left(\Delta_{\mathrm{s} \text {-as }}\right)$ of these two bands of $142 \mathrm{~cm}^{-1}$ is consistent with the type(III) bridging mode of $(-\mathrm{COO}) / \mathrm{Fe}^{\mathrm{III}}$ interactions (Figure 3e). ${ }^{38}$ Similarly, the RR spectrum of $\mathrm{PC} / \mathrm{Fe}^{\mathrm{III}}$ films (Figure 3f) showed features in the region of $1100-600 \mathrm{~cm}^{-1}$ arising from catechol ring vibrations, while the band at $533 \mathrm{~cm}^{-1}$ is characteristic of the catechol/Fe $\mathrm{FII}^{\mathrm{III}}$ chelate ring mode. ${ }^{39}$ An additional feature appeared around $\sim 385 \mathrm{~cm}^{-1}$ (broad), which we tentatively assigned to the $v_{\mathrm{Fe}-\mathrm{O}}$ of $\mu-$ catecholato bridging mode. Considering an average $\mathrm{Fe}-\mathrm{O}$ bond distance $\left(\mathrm{r}_{\mathrm{Fe}-\mathrm{O}}\right)$ of $2.1 \AA$ in $\mu$-catecholato bridging of $\mathrm{Fe}^{\mathrm{III}}$, Badger's rule predicts a $\nu_{\mathrm{Fe}-\mathrm{O}}$ at $\sim 410 \mathrm{~cm}^{-1}$. $^{40-42}$ Note that $\mu$ catecholato/ $\mathrm{Fe}^{\mathrm{III}}$ bridging can also have different coordination modes with an average $\mathrm{r}_{\mathrm{Fe}-\mathrm{O}}$ ranging from 1.87 to $2.18 \AA$, as observed earlier. ${ }^{43}$ The slight discrepancy of bridging $v_{\mathrm{Fe}-\mathrm{O}}$ from Badger's rule in our system is most probably caused by different local environments around the $\mathrm{Fe}^{\mathrm{III}}$ center in the film structure, which might increase the average bridging $\mathrm{r}_{\mathrm{Fe}-\mathrm{O}}$ and shift the bridging $v_{\mathrm{Fe}-\mathrm{O}}$ to a lower frequency. We note that the existence of $\mu$-oxo/hydroxo bridged di/multi-nuclear $\mathrm{Fe}^{\mathrm{III}}$ species (due to hydrolysis of $\mathrm{Fe}^{\mathrm{III}}$ in aqueous solution) in the films may occur, but would be difficult to detect experimentally. ${ }^{44}$

Transition metal-induced oxidative di- or oligomerization of phenolic compounds via $o$-quinone/semiquinone intermediate formation is well established in literature. ${ }^{45,46}$ However, the extent of this process is dependent on several factors, including metal-to-ligand stoichiometry and concentration, reaction $\mathrm{pH}$, and most importantly, reaction time. ${ }^{47-49}$ In this study, the PC/Fe ${ }^{\mathrm{III}}$ system is more vulnerable to this process. Three possibilities can be considered for this system during film formation: 1) PC dimers or higher oligomers are formed initially and later form films through coordinative crosslinking; 2) initially formed PC dimers or higher oligomers, along with PC monomers, formed films through coordinative crosslinking where PC dimers or higher oligomers have a significant contribution to film formation; and 3) PC monomers form films through coordinative crosslinking where PC dimers or higher oligomers have negligible contribution to the film formation. To probe these possibilities, we studied the $\mathrm{PC} / \mathrm{Fe}^{\mathrm{III}}$ complexes in solution (identical conditions used to those for film formation) over time by ESI-MS in negative ion mode (Figure S8). The first measurement was taken at $t=2.5 \mathrm{~min}$ from the time of mixing $(t=0)$. A negligible amount $(\sim 0.4 \%)$ of PC dimers $(\mathrm{m} / \mathrm{z}$ 217.05) was observed at this time point period, which increased only marginally $(\sim 1.5 \%)$ at $t=23$ min compared to the PC monomeric peak ( $\mathrm{m} / \mathrm{z}$ 109.03). Higher oligomeric species were not observed in this timeframe. Therefore, considering the film formation time of $1 \mathrm{~min}$, the first two possibilities for the $\mathrm{PC} / \mathrm{Fe}^{\mathrm{III}}$ system, described above, can largely be excluded, leaving metal coordination with monomeric ligand species as the dominant driver for film formation. Furthermore, negligible covalent crosslinking was observed in several other studies ${ }^{50-52}$ during coordinative gel formation of catechol containing polymers with $\mathrm{Fe}^{\mathrm{III}}$, although the timeframes in those studies were much longer (from 1-12 h). For the GA/Fe ${ }^{\text {III }}$ system, ESI-MS analyses were performed after disassembling the capsules into their molecular fragments by concentrated $\mathrm{HCl}$ treatment. Organic fragments of the $\mathrm{GA} / \mathrm{Fe}^{\mathrm{III}}$ system appeared as a prominent peak at $\mathrm{m} / \mathrm{z} 169.01$ attributed to monomeric GA (Figure S9). Other major peaks observed can be assigned to iron-chloride adducts, as evidenced by their corresponding isotopic patterns. Importantly, no dimeric $(\mathrm{m} / \mathrm{z} 337.02)$ or oligomeric GA species were detected. Similar results were obtained for the $\mathrm{PG} / \mathrm{Fe}^{\mathrm{III}}$ system with the absence of any dimeric or oligomeric PG species.

From the above investigations, network formation in the $\mathrm{GA} / \mathrm{Fe}^{\mathrm{III}}$ and $\mathrm{PC} / \mathrm{Fe}^{\mathrm{III}}$ systems can be viewed in the following manner. For the GA/Fe ${ }^{\text {III }}$ system, carboxylic and hydroxyl groups of GA provide sufficient binding sites for mono and multinuclear $\mathrm{Fe}^{\mathrm{III}}$ species to form a large network by different coordination modes, ${ }^{33,34,38,53}$ as displayed in Figure 3e. For the $\mathrm{PC} / \mathrm{Fe}^{\mathrm{III}}$ system, the vicinal diol groups of PC act as mono and bi-dentate ligands, where the bidentate nature gives rise to mono- and bis-type local complexes ${ }^{29,30}$ with mono and multinuclear $\mathrm{Fe}^{\mathrm{III}}$ species, and the monodentate nature provides the bridging ${ }^{40,41}$ of these complexes allowing network formation (Figure 3g). The dark green coloration of PC-Fe ${ }^{\text {III }}$ complexes usually arises from the formation of mono-type complexes. These discrete complexes are susceptible to redox reactions and discoloration occurs over time by formation of o-quinone/semiquinone intermediates (as mentioned above). In this case, the color of the $\mathrm{PC} / \mathrm{Fe}^{\mathrm{III}}$ capsules (bluish dark green) remained unchanged over 7 days, suggesting that the mono-type complexes present in the films were not discrete entities, but parts of an extended network.

The absence (or negligible presence) of covalent interactions suggests that film formation is a generic coordination phenomenon of phenolic ligand-metal interactions at the solidliquid interface. Interestingly, phenolic ligand/metal pairs are also able to form crystalline framework materials in solution, when phenolic ligands with divergent chelating sites (i.e., ditopic), such as GA, are used. However, formation of crystalline framework materials in solution or surfaceconfined amorphous films at the solid-liquid interface occurs with different kinetics and under different process parameters. One example is the $\mathrm{GA} / \mathrm{Fe}^{\mathrm{III}}$ system, which allows for the production of $\mathrm{GA} / \mathrm{Fe}^{\mathrm{III}} \mathrm{MOF}$ and films (Figure $4 \mathrm{a}, \mathrm{b}$ ). GA/Fe $\mathrm{Fe}^{\mathrm{III}}$ MOFs were produced following a published protocol. ${ }^{34}$ Figure 4c-f displays the differences between the two systems 
containing identical structural components. The SEM image of $\mathrm{GA} / \mathrm{Fe}^{\mathrm{III}}$ MOFs showed needles with crystalline features whereas $\mathrm{GA} / \mathrm{Fe}^{\mathrm{III}}$ films showed amorphous features with folds and creases (Figure 4c,d).
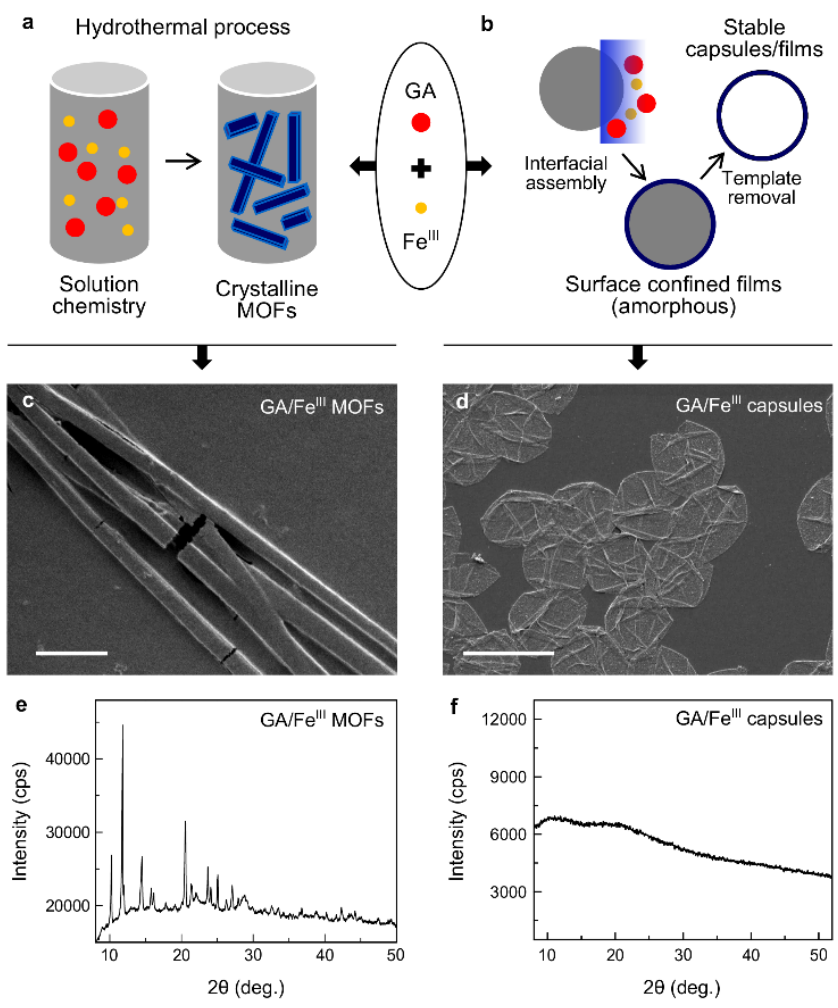

Figure 4. Comparison of the $\mathrm{GA} / \mathrm{Fe}^{\mathrm{III}} \mathrm{MOF}$ and $\mathrm{GA} / \mathrm{Fe}^{\mathrm{III}}$ capsules. Schematic showing formation of (a) crystalline and (b) amorphous materials by $\mathrm{GA} / \mathrm{Fe}^{\mathrm{III}}$ interaction in different conditions. SEM and XRD characterization of GA/Fe ${ }^{\mathrm{III}} \mathrm{MOFs}$ (c, e) and $\mathrm{GA} / \mathrm{Fe}^{\mathrm{III}}$ capsules $(\mathrm{d}, \mathrm{f})$, respectively. Scale bars correspond to $2 \mu \mathrm{m}$ and $3 \mu \mathrm{m}$ for $\mathrm{c}$ and $\mathrm{d}$, respectively.

XRD patterns further support this variation in the supramolecular phases of the two systems, where the periodic arrangements of atoms in the GA/Fe ${ }^{\text {III }}$ MOFs caused prominent Bragg peaks (consistent with the published values) ${ }^{33,34}$ and the aperiodic arrangements of atoms in the $\mathrm{GA} / \mathrm{Fe}^{\text {III }}$ films resulted in broad humps caused by diffuse scattering (Figure 4e,f). Conceptually, these amorphous films are likely to form by a rapid, kinetically dominated nonequilibrium process, while crystalline MOFs are known to form in a slow, kinetically reversible and thermodynamically controlled manner. ${ }^{1,3}$ The thermodynamic and kinetic aspects of these phenolic/metal pairs in producing different stable phases (crystalline and amorphous) may provide fundamental insights into the interfacial and solution phase chemistry of coordination complexes, and require further detailed investigations.

\section{CONCLUSION}

In conclusion, we have demonstrated a simple, rapid and generic surface-confined film formation strategy by utilizing coordination-driven self-assembly of simple phenolic building blocks, such as gallic acid, pyrogallol and pyrocatechol. The structural simplicity of the ligands allowed for a more in-depth evaluation of their contribution to the film formation process. These molecular hybrid films might provide a versatile multifunctional platform for a range of applications, including catalysis, energy and optoelectronics. Moreover, the biological relevance of the phenolic ligands, combined with the dynamic metal-ligand interactions, may make them of interest in the biomedical sciences.

\section{ASSOCIATED CONTENT}

Supporting Information. Details of characterization methods, detailed experimental protocols for film disassembly, permeability, mechanical testing, ESI-MS analyses of the organic fragments of disassembled capsules, synthesis of GA/Fe ${ }^{\mathrm{III}} \mathrm{MOF}$ crystals. EDX spectra of GA/Fe ${ }^{\mathrm{III}}, \mathrm{PG} / \mathrm{Fe}^{\mathrm{III}}$, and $\mathrm{PC} / \mathrm{Fe}^{\mathrm{III}}$ systems, photographs of $\mathrm{GA} / \mathrm{Fe}^{\mathrm{III}}$ films on various templates, characterization of the $\mathrm{PC} / \mathrm{Fe}^{\mathrm{III}}$ system with varying process parameters, photographs of $\mathrm{PC} / \mathrm{Fe}^{\mathrm{III}}$ films on various templates, $\mathrm{UV}-\mathrm{Vis}$ absorbance spectra to determine disassembly kinetics of $\mathrm{GA} / \mathrm{Fe}^{\mathrm{III}}$ and PC/Fe $\mathrm{Fe}^{\mathrm{III}}$ systems, XPS spectra of a $\mathrm{GA} / \mathrm{Fe}^{\mathrm{III}}$ and $\mathrm{PC} / \mathrm{Fe}^{\mathrm{III}}$ systems, RR spectra of GA and PC, time dependent ESIMS spectra of $\mathrm{PC} / \mathrm{Fe}^{\mathrm{III}}$ complex solution, and ESI-MS spectra of disassembled $\mathrm{GA} / \mathrm{Fe}^{\mathrm{III}}$ and $\mathrm{PG} / \mathrm{Fe}^{\mathrm{III}}$ capsules. This material is available free of charge via the Internet at http://pubs.acs.org.

\section{AUTHOR INFORMATION}

\section{Corresponding Author}

* Tel.: +61 38344 3461. Fax: +61 383444153. E-mail: fcaruso@unimelb.edu.au.

\section{Present Addresses}

$\S$ Department of Chemistry, University of Warwick, Coventry, CV4 7AL, UK.

I Institute of Industrial Science, The University of Tokyo, 4-6-1 Komaba, Meguro-ku, Tokyo, Japan.

\# School of Chemistry, The University of Sydney, NSW 2006, Australia.

\section{Author Contributions}

The manuscript was written through contributions of all authors. All authors have given approval to the final version of the manuscript. The authors declare no competing financial interest.

\section{Funding Sources}

This research was funded by the Australian Research Council Centre of Excellence in Convergent Bio-Nano Science and Technology (project number CE140100036). This work was also supported by the Australian Research Council under the Australian Laureate Fellowship (F.C., FL120100030) scheme.

\section{ACKNOWLEDGMENTS}

M.A.R. acknowledges funding from the Australian Government through an International Postgraduate Research Scholarship (IPRS) and an Australian Postgraduate Award (APA). M.M. acknowledges The University of Melbourne for a McKenzie Fellowship. K.K. is grateful to the Alexander von Humboldt Foundation (Feodor-Lynen Fellowship) for financial support. We also acknowledge Dr. Kwun Lun Cho for XPS measurements. This work was performed in part at the Materials Characterisation 
and Fabrication Platform (MCFP) at The University of Melbourne and the Victorian Node of the Australian National Fabrication Facility (ANFF).

\section{ABBREVIATIONS}

AFM, atomic force microscopy; CT, charge transfer; GA, gallic acid; MOF, metal organic framework; PC, pyrocatechol; PG, pyrogallol.

\section{REFERENCES}

(1) Chakrabarty, R.; Mukherjee, P. S.; Stang, P. J. Supramolecular Coordination: Self-Assembly of Finite Two- and Three-Dimensional Ensembles. Chem. Rev. 2011, 111, 6810-6918.

(2) Lehn, J. M. Supramolecular Chemistry: Concepts and Perspectives; VCH: Weinheim, Germany, 1995.

(3) Cook, T. R.; Zheng, Y.-R.; Stang, P. J. Metal-Organic Frameworks and Self-Assembled Supramolecular Coordination Complexes: Comparing and Contrasting the Design, Synthesis, and Functionality of Metal-Organic Materials. Chem. Rev. 2013, 113, 734-77.

(4) Hoskins, B. F.; Robson, R. Infinite Polymeric Frameworks Consisting of Three Dimensionally Linked Rod-Like Segments. J. Am. Chem. Soc. 1989, 111, 5962-5964.

(5) Gable, R. W.; Hoskins, B. F.; Robson, R. A New Type of Interpenetration Involving Enmeshed Independent Square Grid Sheets. The Structure of Diaquabis-(4,4'-bipyridine)zinc Hexafluorosilicate. J. Chem. Soc., Chem. Commun. 1990, 1677-1678.

(6) Foo, M. L.; Matsuda, R.; Kitagawa, S. Functional Hybrid Porous Coordination Polymers. Chem. Mater. 2014, 26, 310-322.

(7) Yaghi, O. M.; O’Keeffe, M.; Ockwig, N. W.; Chae, H. K.; Eddaoudi, M.; Kim, J. Reticular Synthesis and the Design of New Materials. Nature 2003, 423, 705-714.

(8) Eddaoudi, M.; Kim, J.; Rosi, N.; Vodak, D.; Wachter, J.; O’Keeffe, M.; Yaghi, O. M. Systematic Design of Pore Size and Functionality in Isoreticular MOFs and Their Application in Methane Storage. Science 2002, 295, 469-472.

(9) Rosi, N. L.; Eckert, J.; Eddaoudi, M.; Vodak, D. T.; Kim, J.; O'Keeffe, M.; Yaghi, O. M. Hydrogen Storage in Microporous Metal-Organic Frameworks. Science 2003, 300, 1127-1129.

(10) Matsuda, R.; Kitaura, R.; Kitagawa, S.; Kubota, Y.; Belosludov, R. V.; Kobayashi, T. C.; Sakamoto, H.; Chiba, T.; Takata, M.; Kawazoe, Y.; Mita, Y. Highly Controlled Acetylene Accommodation in a Metal-Organic Microporous Material. Nature 2005, 436, 238-241.

(11) Kreno, L. E.; Leong, K.; Farha, O. K.; Allendorf, M.; Van Duyne, R. P.; Hupp, J. T. Metal-Organic Framework Materials as Chemical Sensors. Chem. Rev. 2012, 112, 1105-1125.

(12) Furukawa, H.; Cordova, K. E.; O’Keeffe, M.; Yaghi, O. M. The Chemistry and Applications of Metal-Organic Frameworks. Science 2013, 341, 1230444.

(13) Wang, C.; Liu, D.; Lin, W. Metal-Organic Frameworks as a Tunable Platform for Designing Functional Molecular Materials. $J$. Am. Chem. Soc. 2013, 135, 13222-13234.

(14) Tang, Z.; Wang, Y.; Podsiadlo, P.; Kotov, N. A. Biomedical Applications of Layer-by-Layer Assembly: From Biomimetics to Tissue Engineering. Adv. Mater. 2006, 18, 32033224.

(15) Srivastava, S.; Kotov, N. A. Composite Layer-by-Layer (LBL) Assembly with Inorganic Nanoparticles and Nanowires. Acc. Chem. Res. 2008, 41, 1831-1841.

(16) Liu, Y.; Ai, K.; Lu, L. Polydopamine and Its Derivative Materials: Synthesis and Promising Applications in Energy, Environmental, and Biomedical Fields. Chem. Rev. 2014, 114, 50575115.

(17) Sanchez, C.; Belleville, P.; Popall, M.; Nicole, L. Applications of Advanced Hybrid Organic-Inorganic Nanomaterials: From Laboratory to Market. Chem. Soc. Rev. 2011, 40, 696-753.

(18) Shi, J.; Jiang, Y.; Wang, X.; Wu, H.; Yang, D.; Pan, F.; Su, Y.; Jiang, Z. Design and Synthesis of Organic-Inorganic Hybrid
Capsules for Biotechnological Applications. Chem. Soc. Rev. 2014 43, 5192-5210.

(19) Ejima, H.; Richardson, J. J.; Liang, K.; Best, J. P.; van Koeverden, M. P.; Such, G. K.; Cui, J.; Caruso, F. One-Step Assembly of Coordination Complexes for Versatile Film and Particle Engineering. Science 2013, 341, 154-157.

(20) Guo, J.; Ping, Y.; Ejima, H.; Alt, K.; Meissner, M.; Richardson, J. J.; Yan, Y.; Peter, K.; von Elverfeldt, D.; Hagemeyer, C. E.; Caruso, F. Engineering Multifunctional Capsules through the Assembly of Metal-Phenolic Networks. Angew. Chem., Int. Ed. 2014, 126, 5652-5657.

(21) Ping, Y.; Guo, J.; Ejima, H.; Chen, X.; Richardson, J. J.; Sun, H.; Caruso, F. Ph-Responsive Capsules Engineered from MetalPhenolic Networks for Anticancer Drug Delivery. Small 2015, 11 2032-2036.

(22) Park, J. H.; Kim, K.; Lee, J.; Choi, J. Y.; Hong, D.; Yang, S. H.; Caruso, F.; Lee, Y.; Choi, I. S. A Cytoprotective and Degradable Metal-Polyphenol Nanoshell for Single-Cell Encapsulation. Angew. Chem., Int Ed. 2014, 53, 12420-12425.

(23) Ju, Y.; Cui, J.; Müllner, M.; Suma, T.; Hu, M.; Caruso, F. Engineering Low-Fouling and $\mathrm{pH}$-Degradable Capsules through the Assembly of Metal-Phenolic Networks. Biomacromolecules 2015, 16, 807-814.

(24) Stock, N.; Biswas, S. Synthesis of Metal-Organic Frameworks (MOFs): Routes to Various MOF Topologies, Morphologies, and Composites. Chem. Rev. 2012, 112, 933-969.

(25) Vuong, G.-T.; Pham, M.-H.; Do, T.-O. Direct Synthesis and Mechanism of the Formation of Mixed Metal $\mathrm{Fe}_{2} \mathrm{Ni}-\mathrm{MIL}-88 \mathrm{~B}$. CrystEngComm 2013, 15, 9694-9703.

(26) Bennett, T. D.; Cheetham, A. K. Amorphous MetalOrganic Frameworks. Acc. Chem. Res. 2014, 47, 1555-1562.

(27) Deria, P.; Mondloch, J. E.; Karagiaridi, O.; Bury, W.; Hupp, J. T.; Farha, O. K. Beyond Post-Synthesis Modification: Evolution of Metal-Organic Frameworks Via Building Block Replacement. Chem. Soc. Rev. 2014, 43, 5896-5912.

(28) Caruso, F.; Caruso, R. A.; Möhwald, H. Nanoengineering of Inorganic and Hybrid Hollow Spheres by Colloidal Templating. Science 1998, 282, 1111-1114.

(29) Sever, M. J.; Wilker, J. J. Visible Absorption Spectra of Metal-Catecholate and Metal-Tironate Complexes. Dalton Trans. 2004, 1061-1072.

(30) Perron, N. R.; Brumaghim, J. L. A Review of the Antioxidant Mechanisms of Polyphenol Compounds Related to Iron Binding. Cell Biochem Biophys 2009, 53, 75-100.

(31) Clogston, J. D.; Patri, A. K. In Characterization of Nanoparticles Intended for Drug Delivery; McNeil, S. E., Ed.; Humana Press: New York, NY, 2011; Chapter 6, pp 63-70.

(32) Hunter, R. J. Zeta Potential in Colloid Science: Principles and Applications; Academic Press: London, United Kingdom, 1981.

(33) Wunderlich, C.-H.; Weber, R.; Bergerhoff, G. Über Eisengallustinte. Z. Anorg. Allg. Chem. 1991, 598, 371-376.

(34) Feller, R. K.; Cheetham, A. K. Fe(III), Mn(II), Co(II), and Ni(II) 3,4,5-Trihydroxybenzoate (Gallate) Dihydrates; a New Family of Hybrid Framework Materials. Solid State Sci. 2006, 8, 1121-1125.

(35) Moulder, J. F.; Stickle, W. F.; Sobol, P. E.; Bomben, K. D. Handbook of X-Ray Photoelectron Spectroscopy: A Reference Book of Standard Spectra for Identification and Interpretation of XPS Data; Physical Electronics: Eden Prairie, MN, 1995.

(36) Salama, S.; Stong, J. D.; Neilands, J. B.; Spiro, T. G. Electronic and Resonance Raman Spectra of Iron(III) Complexes of Enterobactin, Catechol, and $N$-Methyl-2,3-dihydroxybenzamide. Biochemistry 1978, 17, 3781-3785.

(37) Lee, A. S.; Mahon, P. J.; Creagh, D. C. Raman Analysis of Iron Gall Inks on Parchment. Vib. Spectrosc. 2006, 41, 170-175.

(38) Nakamoto, K. Infrared and Raman Spectra of Inorganic and Coordination Compounds, Applications in Coordination, Organometallic, and Bioinorganic Chemistry; John Wiley \& Sons, Inc.: Hoboken, NJ, 2009.

(39) Michaud-Soret, I.; Andersson, K. K.; Que, L., Jr.; Haavik, J. Resonance Raman Studies of Catecholate and Phenolate Complexes 
of Recombinant Human Tyrosine Hydroxylase. Biochemistry 1995, 34, 5504-5510.

(40) Grillo, V. A.; Hanson, G. R.; Wang, D.; Hambley, T. W.; Gahan, L. R.; Murray, K. S.; Moubaraki, B.; Hawkins, C. J. Synthesis, X-Ray Structural Determination, and Magnetic Susceptibility, Mössbauer, and EPR Studies of $\left(\mathrm{Ph}_{4} \mathrm{P}\right)_{2}\left[\mathrm{Fe}_{2}(\mathrm{Cat})_{4}\left(\mathrm{H}_{2} \mathrm{O}\right)_{2}\right] \cdot 6 \mathrm{H}_{2} \mathrm{O}$, a Catecholato-Bridged Dimer of Iron(III). Inorg. Chem. 1996, 35, 3568-3576.

(41) Boudalis, A. K.; Dahan, F.; Bousseksou, A.; Tuchagues, J.P.; Perlepes, S. P. Use of the Di-2-pyridyl Ketone/3,5-Di-tertbutylcatechol "Blend" in Iron(III) Chemistry: A Cationic Tetranuclear Cluster and an Anionic Trinuclear Complex. Dalton Trans. 2003, 3411-3418.

(42) Green, M. T. Application of Badger's Rule to Heme and Non-Heme Iron-Oxygen Bonds: An Examination of Ferryl Protonation States. J. Am. Chem. Soc. 2006, 128, 1902-1906.

(43) Boone, S. R.; Purser, G. H.; Chang, H.-R.; Lowery, M. D.; Hendrickson, D. N.; Pierpont, C. G. Magnetic Exchange Interactions in Semiquinone Complexes of Iron. Structural and Magnetic Properties of Tris(3,5-di-tert-butylsemiquinonato)iron(III) and Tetrakis(3,5-di-tert-butylsemiquinonato)tetrakis(3,5-di-tertbutylcatecholato)tetrairon(III). J. Am. Chem. Soc. 1989, 111, 22922299.

(44) Taylor, S. W.; Chase, D. B.; Emptage, M. H.; Nelson, M. J.; Waite, J. H. Ferric Ion Complexes of a Dopa-Containing Adhesive Protein from Mytilus Edulis. Inorg. Chem. 1996, 35, 7572-7577.

(45) Barrett, D. G.; Sileika, T. S.; Messersmith, P. B. Molecular Diversity in Phenolic and Polyphenolic Precursors of Tannin-Inspired Nanocoatings. Chem. Commun. 2014, 50, 7265-7268.

(46) Fullenkamp, D. E.; Barrett, D. G.; Miller, D. R.; Kurutz, J. W.; Messersmith, P. B. pH-Dependent Cross-Linking of Catechols through Oxidation Via $\mathrm{Fe}^{3+}$ and Potential Implications for Mussel Adhesion. RSC Adv. 2014, 4, 25127-25134.

(47) Mentasti, E.; Pelizzetti, E. Reactions between Iron(III) and Catechol (O-Dihydroxybenzene). Part I. Equilibria and Kinetics of Complex Formation in Aqueous Acid Solution. J. Chem. Soc., Dalton Trans. 1973, 2605-2608.

(48) Zeng, H.; Hwang, D. S.; Israelachvili, J. N.; Waite, J. H. Strong Reversible $\mathrm{Fe}^{3+}$-Mediated Bridging between Dopa-Containing Protein Films in Water. Proc. Natl. Acad. Sci. U.S.A 2010, 107, 12850-12853.

(49) Yang, J.; Cohen Stuart, M. A.; Kamperman, M. Jack of All Trades: Versatile Catechol Crosslinking Mechanisms. Chem. Soc. Rev. 2014, 43, 8271-8298.

(50) Holten-Andersen, N.; Harrington, M. J.; Birkedal, H.; Lee, B. P.; Messersmith, P. B.; Lee, K. Y. C.; Waite, J. H. Ph-Induced Metal-Ligand Cross-Links Inspired by Mussel Yield Self-Healing Polymer Networks with near-Covalent Elastic Moduli. Proc. Nat. Acad. Sci. U.S.A 2011, 108, 2651-2655.

(51) Ceylan, H.; Urel, M.; Erkal, T. S.; Tekinay, A. B.; Dana, A.; Guler, M. O. Mussel Inspired Dynamic Cross-Linking of SelfHealing Peptide Nanofiber Network. Adv. Funct. Mater. 2013, 23, 2081-2090.

(52) Yavvari, P. S.; Srivastava, A. Robust, Self-Healing Hydrogels Synthesised from Catechol Rich Polymers. J. Mat. Chem. B 2015, 3, 899-910.

(53) Senvaitiene, J.; Beganskiene, A.; Kareiva, A. Spectroscopic Evaluation and Characterization of Different Historical Writing Inks. Vib. Spectrosc. 2005, 37, 61-67. 
Table of Contents Only

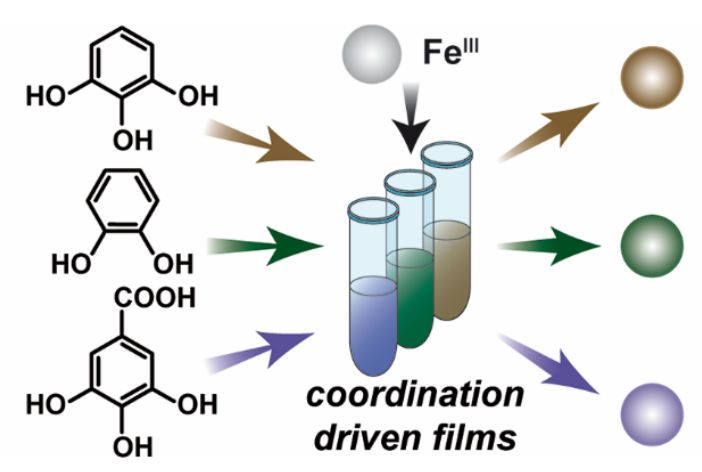




\section{University Library}

\section{$\bullet$ M I N E R VA}

\section{A gateway to Melbourne's research publications}

Minerva Access is the Institutional Repository of The University of Melbourne

\section{Author/s:}

Rahim, MA;Kempe, K;Muellner, M;Ejima, H;Ju, Y;van Koeverden, MP;Suma, T;Braunger, JA;Leeming, MG;Abrahams, BF;Caruso, F

Title:

Surface-Confined Amorphous Films from Metal-Coordinated Simple Phenolic Ligands

Date:

2015-08-25

\section{Citation:}

Rahim, M. A., Kempe, K., Muellner, M., Ejima, H., Ju, Y., van Koeverden, M. P., Suma, T., Braunger, J. A., Leeming, M. G., Abrahams, B. F. \& Caruso, F. (2015). Surface-Confined Amorphous Films from Metal-Coordinated Simple Phenolic Ligands. CHEMISTRY OF MATERIALS, 27 (16), pp.5825-5832. https://doi.org/10.1021/acs.chemmater.5b02790.

Persistent Link:

http://hdl.handle.net/11343/90854 